\title{
ASTEROIDEOS DE LA COLECCIÓN DEL INSTITUTO OCEANOGRÁFICO DE LA UNIVERSIDAD DE SAN PABLO
}

\author{
Irene Bernasconi*
}

Esta nota complementaria se agrega a mis dos contribuciones anteriores publicadas en el Boletim do Instituto Oceanográfico (1955 y 1956).

Incluye la descripción de dos especies tipicamente tropicales; con Echinaster echinophorus (Lam.), completo la lista de especies del género Echinaster, bien representado en las costas brasileñas.

\author{
Fam. Goniasteridae \\ Goniaster americanus Verrill \\ (Lam. I, figs. 1 y 2)
}

Goniaster americanus Verrill 1871, p. 130.

Pentagonaster semilunatus (pars) Perrier 1876, p. 24.

Goniaster americanus Verrill 1899, p. 151. Láms. XXIVa, 1-2; XXVI, 1-6. Goniaster americanus Verril 1915, p. 104. Lám. XIII, 5-5a.

LOCALIDAD - $3^{\circ} 42^{\prime} 5 \mathrm{~N}$ a $3^{\circ} 48^{\prime} 5 \mathrm{~N}-50^{\circ} 37^{\prime} 5 \mathrm{~W}$ a $50^{\circ} 40^{\prime}$ W (frente Isla Maracá y Cabo Cassiporé), profundidad $30 \mathrm{~m}$. Excursión "Toko-Maru". Col. Dr. M. Furuya. 6-IV-1957. Col. Instituto Oceanográfico, SP, n. ${ }^{\circ} 718$.

Un espécimen en seco, $R=72 \mathrm{~mm}, \mathrm{r}=32 \mathrm{~mm}, \mathrm{R}=2,25 \mathrm{r}$.

Forma pentagonal de brazos triangulares alargados y amplios arcos interbraquiales. Superficie abactinal ligeramente convexa,

* Adscripta ad Honoren al Departamento de Zoologia, sección Protozoologia e Invertebrados del Museo Argentino de Ciencias Naturales "Bernardino Rivadavia", Buenos Aires. 
deprimida en las zonas interbraquiales. Placa madrepórica triangular, próxima al centro, rodeada por 3 placas semilunares. Superficie actinal apenas cóncava, con surcos ambulacrales angostos.

Placas abactinales cubiertas por gránulos finos, homogéneos; la mayor parte de ellas llevan púas cónicas, gruesas, romas, que ocupan casi toda la superficie de la placa, rodeada cada una de ellas por una corona de gránulos. Rodeando estas placas hay unos 10-12 orificios papulares, visibles en los brazos, faltan en las zonas interbraquiales. Placa central sin púa, 5 placas radiales con púas; a estas siguen solo 1-3 placas carinales con púas; la serie inmediata está formada por una hilera de $6-8$ placas con púas, luego otra serie de 2-3 placas con púas algo más pequeñas; más afuera puede haber 1-2 púas rudimentarias. El conjunto de púas forma sobre cada brazo un óvalo ensanchado havia el centro y separado del inmediato por una zona interradial formada por un mosaico de placas sin púas. No hay pedicelarios.

Placas súperomarginales grandes, macizas, cuadrangulares, con una fuerte convexidad en forma de tubérculo, más pronunciado en el arco interbraquial; se cuentan 8 placas a cada lado del brazo, los últimos 1-2 pares son contiguos.

Placas ínferomarginales convexas, en mayor número que las anteriores y alternando con ellas, excepto las primeras que son opuestas; se cuentan 12 placas a cada lado, las proximales son ensanchadas; algunas de las distales $\left(9^{*}\right.$ o $\left.11^{a}\right)$ llevan una gruesa púa cónica, roma. Ocasionalmente, en 2 placas observo el surco del pedicelario, de forma semicircular con un poro en el centro. Las placas súperomarginales e ínferomarginales están limitadas por 1-2 círculos de gránulos.

Placas actinolaterales poligonales, densamente cubiertas por gránulos finos y homogéneos; en algunas de las placas, próximas al ángulo oral, sobresale un gránulo como una púa rudimentaria. No observo pedicelarios.

Placas adambulacrales con una serie interna de 4 púas circulares, romas, algo aplanadas transversalmente; luego una serie media de 2 púas gruesas, aplanadas longitudinalmente y una serie externa de 3 púas semejantes; a estas siguen unas 6-7 púas que disminuyen gradualmente de tamaño hasta asemejarse a los gránulos de las placas actinales inmediatas. Del surco de las placas distales adambulacrales, sobresalen algunas púas cónicas, obtusas.

Color del espécimen en seco, ocre en la superficie dorsal y ocre anaranjado en la superficie ventral.

OBSERVACIONES - Por los caracteres indicados, esta especie se identifica con Goniaster americanus Verrill, admitiendo los pe- 
dicelarios como carácter variable, pues el mismo autor reconoce en ejemplares de las Antillas, algunos con pedicelarios y otros, generalmente los mayores, carecen de ellos. Tampoco veo motivos para reunirla con G. africanus Verrill, pues esta tiene placas súperomarginales relativamente más grandes, superficie abactinal casi totalmente cubierta de púas, placas actinales con manojos de 3-6 púas desiguales, etc.

No comparto la opinión de Tortonese (1937, p. 54) de considerar ambas especies idénticas con G. cuspidatus Gray, dando asi demasiada amplitud a los caracteres específicos.

Madsen (1950, p. 209) observa la variabilidad de los caracteres en los especímenes coleccionados en la costa africana y opina, con Perrier, Sladen y Tortonese, que todas ellas pertenecen a una misma especie, ni tampoco se distinguen como variedades. A pesar de la autorizada opinión de Madsen, insisto en considerar $G$. americanus Verrill como especie válida y bien caracterizada.

DISTRIBUCIÓN GEOGRAFICA - Especie tipicamente tropical procedente de S. Carolina, Florida, Antillas. También citada por Rathbun (1879, Brazilian Echinoderms) refiriéndose a Rio de Janeiro.

La localidad "Buenos Aires" citada por Tortonese para G. cuspidatus Gray, me resulta dudosa por la distancia y por estar dicha ciudad sobre el Rio de la Plata. No considerando la sinonimia de Madsen, la localidad Rio de Janeiro indicaria por ahora su límite austral.

\section{Fam. Echinasteridae}

Echinaster echinophorus (Lam.) Perrier

$$
\text { (Lám. II, figs. } 1 \text { y 2) }
$$

Asterias echinophora Lamarck 1816, p. 560.

Echinaster (Othilia) crassispina Verrill 1868, p. 368. Lám. IV, 7.

Echinaster echinophorus Perrier 1875, p. 364.

Echinaster echinophorus Verrill 1915, p. 42.

LOCALIDAD - Arrecife da Lixa, situado aproximadamente 10 millas de la costa de Bahia (Este septentrional de Brasil). Col. Dr. Luís Pini Netto, 10-II-1957. Colección Instituto Oceanográfico, SP, n. ${ }^{\circ}$ 752. Cuatro especímenes (uno en col. M.A.C.N., n. ${ }^{\circ}$ 8345). 
El mayor de ellos mide $\mathrm{R}=52 \mathrm{~mm}, \mathrm{r}=11 \mathrm{~mm}, \mathrm{R}=4,7 \mathrm{r}$. Brazos bien contorneados, rectos, algo convexos en la cara abactinal y aplanados en la actinal, cubiertos por gruesa piel. En cada brazo se cuenta en total, unas 7 hileras de placas con púas cónicas, distribuídas asi: 3 hileras abactinales algo irregulares, luego a cada lado del brazo una hilera de placas súperomarginales que forman el borde espinoso del brazo; ventralmente hay una hilera a cada lado, de placas ínferomarginales casi adyacentes a las adambulacrales, pues la serie actinal casi pasa desapercibida en la mitad proximal del brazo. Placa madrepórica circular, próxima al centro, sin caracteres diferenciales. Numerosas áreas papulares con poros grandes, distribuídas en el disco y entre las hileras de placas abactinales; en las zonas intermarginales tienen menor número de poros.

Placas súperomarginales con púas cónicas, agudas, erectas o algo arqueadas hacia arriba y mamelonares en su base; están separadas de las placas abactinales por amplias áreas papulares. Las placas ínferomarginales se inician en el ángulo oral y llevan una púa semejante (a veces 2), forman una hilera casi adyacente a la adambulacral, de la cual está separada por la hilera actinolateral poco aparente, por estar desprovista de púas y escondida bajo la piel.

En el ángulo interbraquial, las placas actinolaterales forman áreas desnudas, de piel lisa, excepcionalmente con algunas púas pequeñas. Hay áreas papulares en las zonas intermarginales y poros aislados en la superficie actinal.

Placas adambulacrales con 2 series de púas cilíndricas, romas; la serie externa de púas más largas, forman una hilera longitudinal regular; además hay una púa interna rudimentaria en el surco y que puede pasar desapercebida.

Color en seco, pardo púrpura, algo más claro ventralmente.

OBSERVACIONES - Los cuatro ejemplares coinciden en sus caracteres específicos, dependiendo su mayor nitidez, del estado de conservación de la piel, por ejemplo: las placas granulosas de la superficie abactinal con púas de base mamelonar, a veces reemplazadas por 2-4 púas pequeñas; el área actinal interbraquial desnuda, etc.

DisTRIBUCIÓN GEOGRAFICA - Es común en aguas poco profundas y en los arrecifes de Antillas, Bahamas, Yucatán. Hacia el sur se encuentra en las costas brasileñas, siendo especie abundante en Paraíba, Pernambuco, Abrolhos, Bahia. 


\section{R ES U M O}

Representa o presente artigo uma nota complementar ao trabalho que a autora vem realizando a respeito dos Equinodermas da coleção do Instituto Oceanográfico.

Nela a autora faz referência a mais duas espécies, uma coletada no cruzeiro do "Toko-Maru", entre a Ilha de Maracá e o Cabo Cassiporé $\left(3^{\circ} 42^{\prime} 5\right.$ a $3^{\circ} 48^{\prime} 5 \mathrm{~N} \cdot 50^{\circ} 37^{\prime} 5$ a $50^{\circ} 40^{\prime}$ W) e outra proveniente do Arrecife da Lixa, situado aproximadamente a 10 milhas da costa da Bahia.

\section{B I B L I O G R A F I A}

BERNASCONI, I.

1955. Equinoideos y Asteroideos de la colección del Instituto Oceanográfico de la Universidad de San Pablo. Primeira contribución. Bol. Inst. Ocean., vol. 6 , fasc. $1 / 2$, p. 51-91, láms. I-VII.

1956. Ibid. Segunda contribución. Bol. Inst. Ocean., vol. 7, fasc. 1/2, p. 119-149, láms. I-IV.

Clark, H. L.

1933. Littoral Echinoderms of Puerto Rico. N. York Acad. Sci., vol. XVI, part 1, p. 1-147, láms. I-VII.

LAMARCK, A. de

1816. Histoire naturelle des animaux sans vertèbres. II.

Madsen, F. J.

1950. The Echinoderms collected by the Atlantide-Expedition 1945-46.

I. Asteroidea. Atlantide Report, n. ${ }^{\circ} 1$, p. 167-222, láms. XIVXVI.

Perrier, E.

1875. Revision des Stellérides du Museum. Arch. Zool. Exp., vol. IV, p. 265-450.

1876. Ibid. Arch. Zool. Exp., vol. V, p. 1-104.

TORTONESE, E.

1937. Gli Echinodermi del Museo di Torino. Asteroidi. Boll. Mus. Zool. Anat. Comp. Univ. Torino, vol. XLV, p. 27-132, láms. I-XI. 1935-36.

Verrill, A. E.

1868. Notice of the Corals and Echinoderms collected by Prof. Hartt, at the Abrolhos Reef, Prov. of Bahia, Brazil, 1867. Trans. Conn. Acad. Arts of Sci., vol. I, p. 351-371, lám. IV.

1871. Descriptions of starfishes and ophiurans from the Atlantic coasts of America and Africa. Amer. Jour. Sci. and Arts, vol. II, n. ${ }^{\circ}$ 3 , p. $130-132$.

1899. Revision of certain genera and species of starfishes with descriptions of new forms. Trans. Conn. Acad. Arts and Sci., vol. X, p. 145-234, láms. XXIV-XXX.

1915. Report on the starfishes of the West Indies, Florida and Brazil. Bull. Univ. Iowa, vol. VII, n. ${ }^{\circ} 1$, p. 1-232, láms. I-XXIX. 
$-18-$

L Å MINA I

Figs. 1 y 2 - Goniaster americanus Verrill, aboral y oral. 

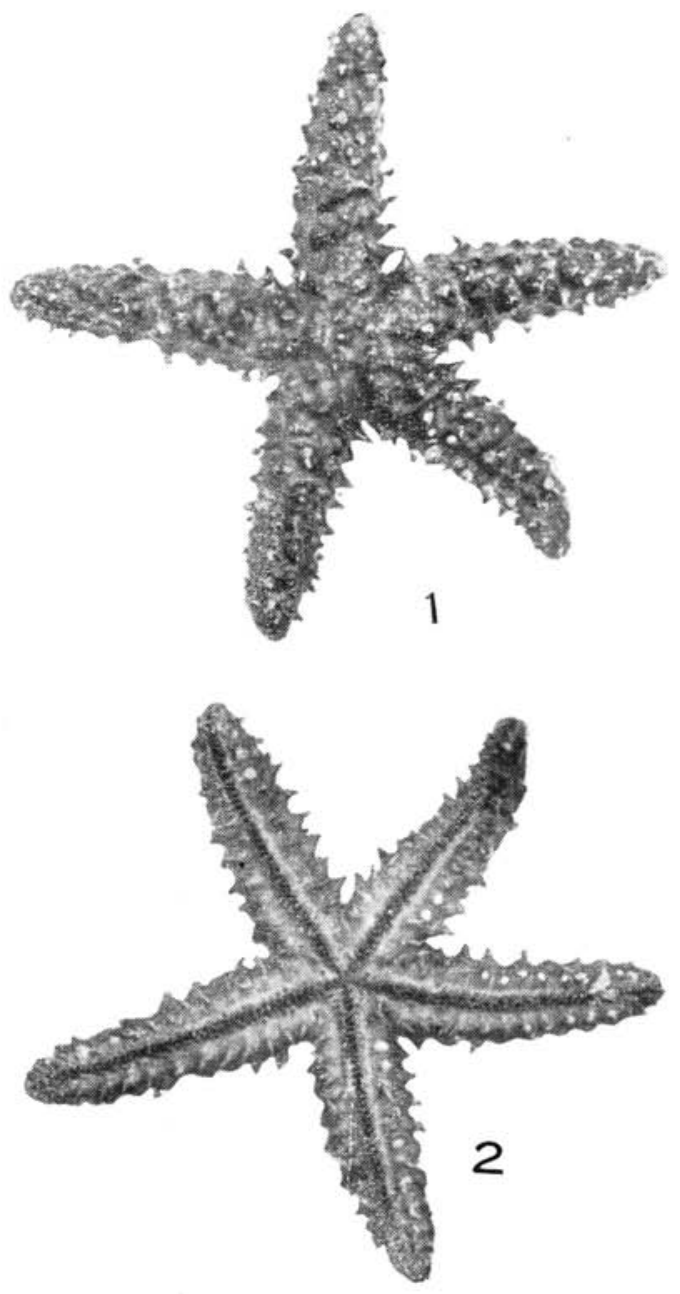
$-20-$

L A M I N A II

Figs. 1 y 2 - Echinaster echinophorus (Lam.) Perrier, aboral y oral. 

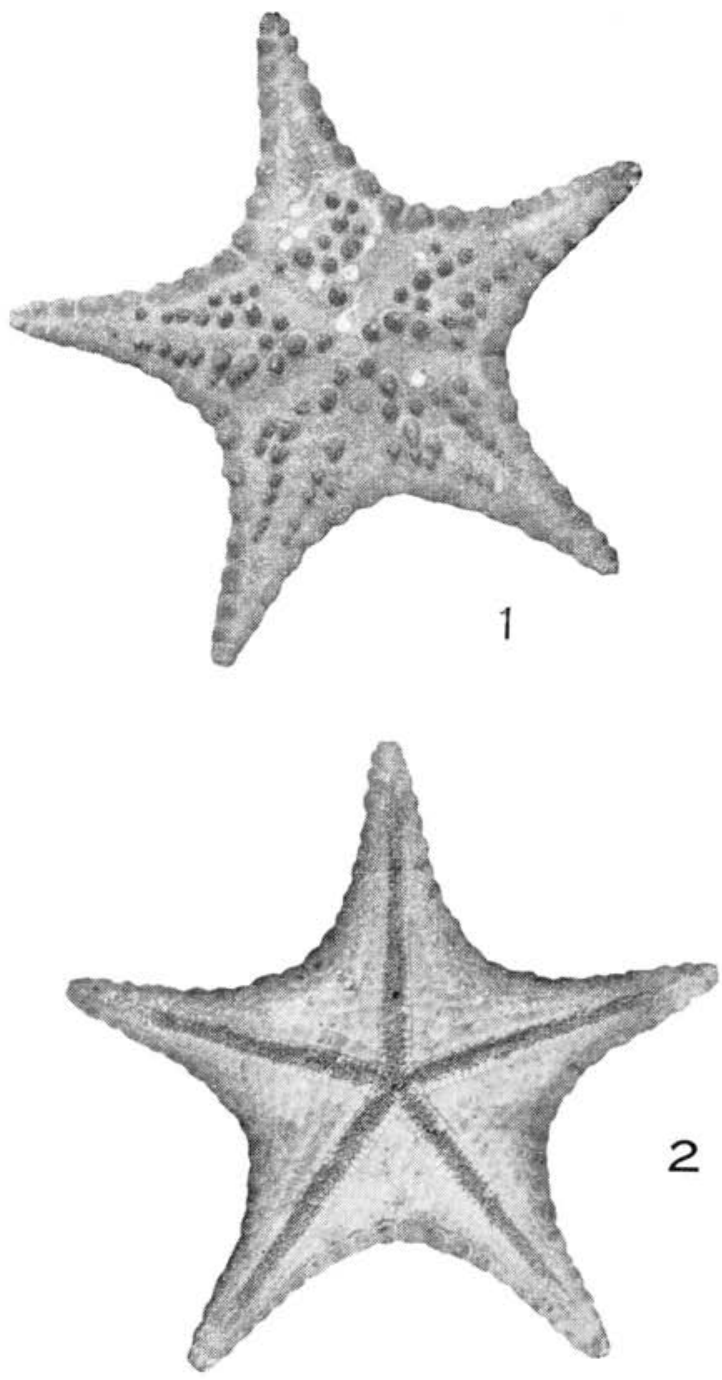